\title{
Modeling and Optimization of Shell and Tube Heat Exchanger in Treatment Unit of South Pars Fifth Refinery by Fluent Software
}

\author{
Kazem Moaveni", Mehran Zarkesh \\ Department of Mechanic, Dashtestan Branch, Islamic Azad University, Borazjan, Iran \\ Email address: \\ kazemmoaveni@gmail.com (K. Moaveni) \\ ${ }^{*}$ Corresponding author
}

\section{To cite this article:}

Kazem Moaveni, Mehran Zarkesh. Modeling and Optimization of Shell and Tube Heat Exchanger in Treatment Unit of South Pars Fifth Refinery by Fluent Software. American Journal of Mechanical and Industrial Engineering. Vol. 2, No. 4, 2017, pp. 150-161.

doi: 10.11648/j.ajmie.20170204.11

Received: April 11, 2017; Accepted: April 21, 2017; Published: July 4, 2017

\begin{abstract}
In this thesis, the numerical solution of navier stockes equations and turbulent equations have also been investigated in fluent software, to investigate baffle type change from cut off to helical in shell and tube heat exchanger. RNG $\mathrm{K}-\varepsilon$ turbulence model was used to perturbations modelling. The main objective of baffle changing in thesis is increasing propane temperature in pipes outlet. 4 heat exchanger type with different helical angles $(35,40,45$ and 50) compared with simple baffle type. Studies indicate that heat exchanger with helical angle of $50^{\circ}$, maximum outlet temperature of propane will result and have the maximum heat transfer rate in shell. Exchangers with helical angle of 40 degrees have the highest ratio h / $\Delta \mathrm{p}$, which reflects the heat transfer rate to pressure drop ratio.
\end{abstract}

Keywords: Optimization, Shell and Tube Heat Exchanger, Treatment Unit, Fluent Software

\section{Introduction}

Equipments used in the heat transfer, defined, according to the operation in the process of doing. heat exchanger, heat between two streams of the process to recovery. steam and cold water are used as ancillary services but such as streams can recover them in the process, not studied.

Heaters for heating of fluids used in the process and often from steam water as the heating fluids is used. however in oil refineries, from hot oil is used in the current cycle for heating and for the cooling of fluids, the dispenser is used and cold water acts as a cooling intermediate matter.

Condenser is kind of cooling but the purpose of using it is to take of the fluid sensible heat.

The purpose of the use of the reboiler, is the necessary heat supply in distillation process as latent heat.

In this study, a shell and tube heat exchanger that used the two fluids of water steam in the shell and propane in the tube, the numerical analysis are considered.

\section{Governing Equations}

In the chapter, is described, equations and models used in the numerical solution of flow in the heat exchangers. these equation are include, continuity equation, momentum, energy and turbulence equations that to continue with the introduction of them.

\subsection{Fluid Flow Relations}

In general, Governing equations of viscous flows, are navier-stokes and continuity equations.

When the flow is turbulent, transition move of the fluid particles, identifies non- permanent of flow. so, for the numerical solution of equations, must size of time step in calculation, be considered much smaller of time scales of turbulence. it is also necessary, numerical calculation to be performed in the network that dimensions each of its components, is much smaller than the length scale of turbulence. (Anderson 1998).

In most engineering problems, no need to study the particles transition and detail the structure of turbulence and 
usually, the average time of turbulent flows, will be examined. for this purpose, instead of navier - stokes equations is used time-averaged equations. these equations by replacing the relations $V_{i}=\bar{V}_{l}+V_{i}^{\prime}, P=\bar{P}+P^{\prime}$ in the navier - stokes equations and after applying the operator of time-averaged obtained. in this relations are $\bar{V}_{l}, \bar{P}$, respectively, the average time of collective velocities and pressure and are $V^{\prime}, \mathrm{P}^{\prime}$, secondary speeds or incident of particles and pressure accidental changes.

Unlike conventional definition, for turbulent flow properties where each property of flow is distinct into two part, stream of the average amount of time and the amount of fluctuation.

For compressible flow by defining the average variables of mass weight as:

$$
\widetilde{f}=\frac{\overline{\rho f}}{\bar{\rho}}
$$

Instead of the time average amount of turbulent flow properties from gathering of average variables of mass and swinging components $f^{\prime \prime}$ are obtained that unlike time average mode, time components are not zero.

$$
f=\tilde{f}+f^{\prime \prime}
$$

As such, time-average operator is defined as:

$$
\tilde{f}=\frac{1}{\Delta t} \int_{t_{0}}^{t_{0}+\Delta t} f d t
$$

It is noteworthy that average variables of mass weight used only for velocities and temperature components and other quantities such as pressure and density calculated as before.

By replacing the components of turbulent flow (result from the mass average variables) flow equations can be obtained as follows:

Continuity equation:

$$
\frac{\partial \bar{\rho}}{\partial t}+\frac{\partial}{\partial x_{j}}\left(\bar{\rho} u_{j}\right)=0
$$

momentum equation:

$$
\frac{\partial}{\partial t}\left(\bar{\rho} \tilde{u}_{i}\right)+\frac{\partial}{\partial x_{j}}\left(\bar{\rho} \tilde{u}_{i} \tilde{u}_{i}\right)=-\frac{\partial p}{\partial x_{i}}+\frac{\partial}{\partial x_{j}}\left(\widetilde{\tau_{l \jmath}}-\rho \overline{u_{\imath}^{\prime \prime} u_{\jmath}^{\prime \prime}}\right)
$$

energy equation:

$$
\frac{\partial}{\partial t}(\bar{\rho} \widetilde{H})+\frac{\partial}{\partial x_{j}}\left(\bar{\rho} \tilde{u}_{j} \widetilde{H}+\overline{\rho^{\prime} u_{\jmath}^{\prime \prime} H^{\prime \prime}}-k \frac{\partial \bar{T}}{\partial x_{j}}\right)=-\frac{\partial p}{\partial t}+\frac{\partial}{\partial x_{j}}\left(\widetilde{u_{\imath}} \widetilde{\tau_{\imath \jmath}}+\overline{u_{l}^{\prime \prime} \tau_{\imath \jmath}}\right)
$$

That:

$$
\widetilde{\tau_{l j}}=\mu\left[\left(\frac{\partial \widetilde{u_{l}}}{\partial x_{j}}+\frac{\partial \widetilde{u_{j}}}{\partial x_{i}}\right)-\frac{2}{3} \delta_{i j} \frac{\partial \widetilde{u_{k}}}{\partial x_{k}}\right]+\mu\left[\left(\frac{\partial \overline{u_{l}^{\prime \prime}}}{\partial x_{j}}+\frac{\partial \overline{u_{J}^{\prime \prime}}}{\partial x_{i}}\right)-\frac{2}{3} \delta_{i j} \frac{\partial \overline{u_{k}^{\prime \prime}}}{\partial x_{k}}\right]
$$

Problems solution related to viscous flows by navierstokes equations of simplification, accuracy is not high. during that there is interaction between viscous and nonviscous areas and flow separation, it is necessary for solution of navier-stokes full equations that this method is timeconsuming and costly. (Anderson 1998).

Usually numerical methods for solving navier-stokes equations, is such as solution methods of Euler equations.

If $\mathrm{t}$, the time display and were $\rho, \mathrm{p}, \mathrm{T}$, respectively represent the density, pressure and temperature, complimentary U, V, W as velocities in Cartesian coordinates $(\mathrm{X}, \mathrm{Y}, \mathrm{Z})$, navier-stokes equations of 3D (three-dimensional) in curvilinear coordinates are defined as follows:

$$
\begin{gathered}
\partial_{t} \tilde{Q}+\partial_{\xi}\left(\tilde{E}-\widetilde{E_{v}}\right)+\partial_{\eta}\left(\tilde{F}-\widetilde{F_{v}}\right)+\partial_{\zeta}\left(\tilde{G}-\widetilde{G_{v}}\right)=0 \\
\tilde{Q}=\left(\begin{array}{c}
\rho \\
\rho u \\
\rho v \\
\rho w \\
e
\end{array}\right) \\
\tilde{E}=h\left(\begin{array}{c}
\rho U \\
\rho U u+\xi_{x} p \\
\rho U v+\xi_{y} p \\
\rho U w+\xi_{z} p \\
U(e+p)
\end{array}\right)
\end{gathered}
$$

$$
\begin{array}{r}
\tilde{F}=h\left(\begin{array}{c}
\rho V \\
\rho V u+\eta_{x} p \\
\rho V v+\eta_{y} p \\
\rho V w+\eta_{z} p \\
V(e+p)
\end{array}\right) \\
\tilde{G}=h\left(\begin{array}{c}
\rho W \\
\rho W u+\zeta_{x} p \\
\rho W v+\zeta_{y} p \\
\rho W w+\zeta_{w} p \\
W(e+p)
\end{array}\right)
\end{array}
$$

That $\mathrm{Q}$ is the conservative variable vector and $\widetilde{G}, \widetilde{F}, \widetilde{E}$ are displacement fluids vector and $\widetilde{E_{v}}, \widetilde{F_{v}}, \widetilde{G_{v}}$ are viscous fluids vector and also, e introduced the total energy. (Anderson 1998).

The contract velocities components $\mathrm{U}, \mathrm{V}, \mathrm{W}$, as defined below:

$$
\begin{aligned}
& U=\xi_{x} u+\xi_{y} v+\xi_{z} w \\
& V=\eta_{x} u+\eta_{y} v+\eta_{z} w \\
& W=\zeta_{x} u+\zeta_{y} v+\zeta_{z} w
\end{aligned}
$$

The equation of state is used for the complete system of equation, the compressible flow:

$$
p=(\gamma-1)\left[e-\frac{1}{2} \rho\left(u^{2}+v^{2}+w^{2}\right)\right]
$$


That $\gamma$ Is the ratio of specific heat coefficient and also, $\mathrm{h}$ is reversed of the transfer Jacobins:

$$
h=\left|\begin{array}{lll}
x_{\xi} & x_{\eta} & x_{\zeta} \\
y_{\xi} & y_{\eta} & y_{\zeta} \\
z_{\xi} & z_{\eta} & z_{\zeta}
\end{array}\right|
$$

Viscous fluids vectors are include:

$$
\begin{aligned}
& \widetilde{E_{v}}=h\left[\xi_{x} E_{v}+\xi_{y} F_{v}+\xi_{z} G_{v}\right] \\
& \widetilde{F_{v}}=h\left[\eta_{x} E_{v}+\eta_{y} F_{v}+\eta_{z} G_{v}\right] \\
& \widetilde{G_{v}}=h\left[\zeta_{x} E_{v}+\zeta_{y} F_{v}+\zeta_{z} G_{v}\right]
\end{aligned}
$$

In Cartesian coordinates:

$$
\begin{aligned}
& E_{v}=\left[\begin{array}{c}
0 \\
\tau_{x x} \\
\tau_{x y} \\
\tau_{x z} \\
u \tau_{x x}+v \tau_{x y}+w \tau_{x z}-k \partial_{x} T
\end{array}\right] \\
& F_{v}=\left[\begin{array}{c}
0 \\
\tau_{y x} \\
\tau_{y y} \\
\tau_{y z} \\
u \tau_{y x}+v \tau_{y y}+w \tau_{y z}-k \partial_{y} T
\end{array}\right] \\
& G_{v}=\left[\begin{array}{c}
0 \\
\tau_{z x} \\
\tau_{z y} \\
\tau_{z z} \\
u \tau_{z x}+v \tau_{z y}+w \tau_{z z}-k \partial_{z} T
\end{array}\right] \\
& \tau_{x x}=2 \mu \partial_{x} u-\frac{2}{3} \mu\left(\partial_{x} u+\partial_{y} v+\partial_{z} w\right) \\
& \tau_{y y}=2 \mu \partial_{y} v-\frac{2}{3} \mu\left(\partial_{x} u+\partial_{y} v+\partial_{z} w\right) \\
& \tau_{z z}=2 \mu \partial_{z} w-\frac{2}{3} \mu\left(\partial_{x} u+\partial_{y} v+\partial_{z} w\right) \\
& \tau_{x y}=\tau_{y x}=\mu\left(\partial_{y} u+\partial_{x} v\right) \\
& \tau_{x z}=\tau_{z x}=\mu\left(\partial_{z} u+\partial_{x} w\right) \\
& \tau_{y z}=\tau_{z y}=\mu\left(\partial_{z} v+\partial_{y} w\right)
\end{aligned}
$$

Correlation coefficient of viscosity $(\mu)$ and heat transfer coefficient $(\mathrm{k})$ is defined as:

$$
k=\frac{y}{y-1}\left(\frac{\mu}{P r}\right)
$$

Prandtl number (pr), is laminar flow.

By replacing time-averaged quantities total and swinging instead if physical quantities in navier-stokes equations, appear new unknowns in the equations. for complete the system of equations need to add new equation to model of additional phrases. additional introduced new relationships for complete the system of equations called turbulence models. (Anderson 1998).

\subsection{Turbulent Flow Models}

Turbulent flow models can be classified as follows: (Wilcox 1994)

1) Algebraic models of turbulent viscosity (Zero-equation models)

2) Differential models of turbulent viscosity (the singleequation and two equation)

3) Reynolds stress models (Differential and algebraic turbulence models)

4) large eddy simulation of turbulence

5) direct simulation of turbulence( without the use of turbulence models)

Zero-equation models, only the relationships and algebraic equations to describe the relationship between $\mu_{t}$ and the calculated properties and or measurable used. A equation models, in this between uses from a transport equation of additional PDE. Two-equation models are included two additional PDE.

In the categories of first and second used Boussinesq theory. The means that turbulence tensions calculate according to the stokes viscosity law and flows like to laminar flows.

$$
-\rho \overline{u_{\imath}{ }^{\prime} u_{\jmath}^{\prime}}=\mu_{t}\left(\frac{\partial \overline{u_{l}}}{\partial x_{j}}+\frac{\partial \overline{u_{j}}}{\partial x_{i}}\right)
$$

Where $\mu_{t}$ is turbulence viscosity.

In the third category, directly, obtained turbulence tensions that are from number of transfer equations or differential or algebraic.

In the fourth category, to a certain size of the vortices are examined without of model and for they to solve navierstokes equations in non-permanent state but the model small vortices.

In the fifth category, turbulent flow are examined without modeling and by solving the navier-stokes equations of nonpermanent with in view of the very small distance of time and place turbulence flow is studied.

The last two methods requires the use of very fast computers and generally limited to simple mode and low Reynolds number. because is used in research from two category, so we just preferred to these models.

\subsubsection{Single-Equation Model: Spalart-Allmaras}

Model Spalart-Allmaras is model of one simple equation that solve a model equation of transfer for get $\mu_{t}$.

Model Spalart-Allmaras, effective model for low Reynolds number is considered, the effective use of this model, is limited to affected areas by the viscosity in inside of the boundary layer and similar areas.

\subsubsection{Two-Equation Model}

Two-equation models, as a lot of research infrastructure, related to the modeling of turbulent flow, especially in recent years, much has been attention. (Wilcox 1994). in the following, express, some of popular models of this category. 


\section{i. Model $k-\varepsilon$}

Model k- $\varepsilon$, is the most popular of two-equation model. because it is easy to understand and use it in the program is simple. in models k- $\varepsilon$ Eddy-Viscosity, the turbulent square by two variables can be expressed. (Wilcox 1994)

a. The kinetic energy of turbulent $(\mathrm{k})$

b. Slimy dissolution rate of the kinetic energy of turbulent flow $(\varepsilon)$

$$
\begin{gathered}
k=\frac{1}{2} \overline{u_{\imath}^{\prime} u_{\imath}^{\prime}} \\
\varepsilon=\left(\frac{\mu}{\rho}\right) \overline{u_{l, \jmath}^{\prime} u_{l, \jmath}^{\prime}}
\end{gathered}
$$

Can by help of dimensional analysis showed that turbulent viscosity $\left(\mu_{t}\right)$ can be linked to the large Eddy scale length of turbulent flow.

$$
\mu_{t} \propto \rho u_{l} \delta_{l}
$$

Where in $u_{l}$ and $\delta_{l}$, are respectively, the speed and length of scale in the biggest Eddy on field of the turbulent flow. in addition, it can be shown that:

$$
\begin{aligned}
& u_{l} \propto \sqrt{k} \\
& \delta_{l} \propto \frac{\sqrt{k^{3}}}{\varepsilon}
\end{aligned}
$$

As a result:

$$
\mu_{t}=C_{\mu} \rho \frac{k^{2}}{\varepsilon}
$$

Where in $C_{\mu}$, is an experimental coefficient that its value is usually considered equal to 0.9 . in the standard model $\mathrm{k}-\varepsilon, \mathrm{k}$ and $\varepsilon$, obtained by semi- experimental equations below:

$$
\begin{gathered}
\frac{\partial}{\partial t}(\bar{\rho} k)+\frac{\partial}{\partial x_{j}}\left(\bar{\rho} \bar{u}_{j} k\right)=\frac{\partial}{\partial x_{j}}\left[\left(\mu+\frac{\mu_{t}}{\sigma_{k}}\right) \frac{\partial k}{\partial x_{j}}\right]+G-\rho \varepsilon-2 \rho \varepsilon M_{t}^{2} \\
\frac{\partial}{\partial t}(\bar{\rho} \varepsilon)+\frac{\partial}{\partial x_{j}}\left(\bar{\rho} \bar{u}_{j} \varepsilon\right)=\frac{\partial}{\partial x_{j}}\left[\left(\mu+\frac{\mu_{t}}{\sigma_{\varepsilon}}\right) \frac{\partial \varepsilon}{\partial x_{j}}\right]+C_{1} \frac{\varepsilon}{k} G-C_{2} \rho \frac{\varepsilon^{2}}{k}
\end{gathered}
$$

Where in $C_{1}$ and $C_{2}$ have been experimental coefficients and $\sigma_{k} g \sigma_{\varepsilon}$ are respectively, prandtl numbers and turbulent Schmidt.

Terms $C_{1} \frac{\varepsilon}{k} G$ and $C_{2} \rho \frac{\varepsilon^{2}}{k}$, respectively are, represent of the processes of shear production $\varepsilon$ and viscose filament processes $\varepsilon$. in the above equations, buoyancy effects is not considered.

Term $G$, is represents of production rate of the turbulent kinetic energy, due to interaction, between the average flow and turbulent flow field and for this purpose, the called shear production term. according to:

$$
G=-\rho u_{i}^{\prime} u_{j}^{\prime} \frac{\partial u_{i}}{\partial x_{j}}
$$

according to the hypothesis Boussinesq:

$$
-\rho \overline{u_{\imath}^{\prime} u_{\jmath}^{\prime}}=\mu_{t}\left[\frac{\partial u_{j}}{\partial x_{i}}+\frac{\partial u_{i}}{\partial x_{j}}-\frac{2}{3} \delta_{i j} \frac{\partial u_{k}}{\partial x_{k}}\right]-\frac{2}{3} \rho k \delta_{i j}
$$

That $\mu_{t}$ is turbulent viscosity coefficient and used for

$$
\begin{gathered}
\frac{\partial}{\partial t}(\bar{\rho} k)+\frac{\partial}{\partial x_{j}}\left(\bar{\rho} \bar{u}_{j} k\right)=\frac{\partial}{\partial x_{j}}\left[\left(\mu+\frac{\mu_{t}}{\sigma_{k}}\right) \frac{\partial k}{\partial x_{j}}\right]+G-\rho \varepsilon-2 \rho \varepsilon M_{t}^{2} \\
\frac{\partial}{\partial t}(\bar{\rho} \varepsilon)+\frac{\partial}{\partial x_{j}}\left(\bar{\rho} \bar{u}_{j} \varepsilon\right)=\frac{\partial}{\partial x_{j}}\left[\left(\mu+\frac{\mu_{t}}{\sigma_{\varepsilon}}\right) \frac{\partial \varepsilon}{\partial x_{j}}\right]+C_{1} \frac{\varepsilon}{k} G-C_{2} \rho \frac{\varepsilon^{2}}{k}-\frac{C_{\mu} \eta^{3}\left(1-\frac{\eta}{\eta_{0}}\right)}{1+\beta \eta^{3}} \frac{\varepsilon^{2}}{k}
\end{gathered}
$$

Parameter $\eta$, is represents of the turbulent characteristic time ratio, to flow field characteristic time. so, this model has determined, effects of Off-Equilibrium.

$$
\begin{gathered}
\eta=S \frac{k}{\varepsilon} \text { Where } S=\sqrt{2 S_{i j} S_{i j}}=\sqrt{\frac{G}{\mu_{t}}}, \\
S_{i j}=\frac{1}{2}\left(\frac{\partial u_{j}}{\partial x_{i}}+\frac{\partial u_{i}}{\partial x_{j}}\right)
\end{gathered}
$$

It can be shown that $\eta$ is function of the ratio $\frac{\text { Generation of } k}{\text { Dissipation of } k}$ and it can be stated as follows:

$$
\eta=\sqrt{C_{\mu}^{-1} \frac{G}{\rho \varepsilon}}
$$

The main coefficients of model RNG for isothermal process are: $\sigma_{k}, \sigma_{\varepsilon}, C_{1}, C_{2}, C_{\mu}$. coefficients $\eta_{0}$ and $\beta$ can obtained directly using the these coefficients and constant von Karman. 
Yakhut and his colleagues, proposed the following coefficients for this model:

Table 1. The main coefficients of model RNG for isothermal process.

\begin{tabular}{lllllll}
\hline $\boldsymbol{\sigma}_{\boldsymbol{k}}$ & $\boldsymbol{\sigma}_{\boldsymbol{\varepsilon}}$ & $\boldsymbol{C}_{\mathbf{1}}$ & $\boldsymbol{C}_{\mathbf{2}}$ & $\boldsymbol{C}_{\boldsymbol{\mu}}$ & $\boldsymbol{\eta}_{\mathbf{0}}$ & $\boldsymbol{\beta}$ \\
\hline 0.7179 & 0.7179 & 1.42 & 1.68 & 0.085 & 4.38 & 0.015 \\
\hline
\end{tabular}

\section{iii. $k$ - $\omega$ Model Wilcox}

Basic mode of models k- $\omega$ from turbulence frequency $\omega$, instead of rate of slimy collapse $\varepsilon$, used for determine of turbulence. (Wilcox 1998)

In model Wilcox $k-\omega$, the relationship between the length and speed turbulence scale, the $\delta_{t}$ and $u_{t}$ with $k$ and $\omega$ shown by the following equation:

$$
\begin{array}{r}
\delta_{t} \propto \frac{\sqrt{k}}{\omega} \\
u_{t} \propto \sqrt{k}
\end{array}
$$

As can be seen, changes in the basic relationships and scales length and .... Can not be seen. the turbulence frequency can be set by phrase $\varepsilon=\omega k$ to terms $k$ and $\omega$ and turbulent viscosity is obtained by the following equation:

$$
\mu_{t}=C_{\mu} \rho \frac{k}{\omega}
$$

Transport equations for $k, \omega$ in model Wilcox, for compressible flow, are:

$$
\begin{gathered}
\frac{\partial}{\partial t}(\bar{\rho} k)+\frac{\partial}{\partial x_{j}}\left(\bar{\rho} \bar{u}_{j} k\right)=\frac{\partial}{\partial x_{j}}\left[\left(\mu+\frac{\mu_{t}}{\sigma_{k}}\right) \frac{\partial k}{\partial x_{j}}\right]+G-\rho \beta^{*} f_{\beta^{*}} k \omega \\
\frac{\partial}{\partial t}(\bar{\rho} \omega)+\frac{\partial}{\partial x_{j}}\left(\bar{\rho} \bar{u}_{j} \omega\right)=\frac{\partial}{\partial x_{j}}\left[\left(\mu+\frac{\mu_{t}}{\sigma_{\omega}}\right) \frac{\partial \omega}{\partial x_{j}}\right]+\alpha \frac{\omega}{k} G-\rho \beta f_{\beta} \omega^{2}
\end{gathered}
$$

according to coefficient $\alpha$ :

$$
\alpha=\frac{\alpha_{\infty}}{\alpha^{*}}\left(\frac{\frac{1}{9}+\frac{R e_{t}}{2.95}}{1+\frac{R e_{t}}{2.95}}\right)
$$

that $\alpha^{*}$ are:

$$
\alpha^{*}=\alpha_{\infty}^{*}\left(\frac{\frac{0.072}{3}+\frac{R e_{t}}{6}}{1+\frac{R e_{t}}{6}}\right)
$$

That:

$$
R e_{t}=\frac{\rho k}{\mu \omega}, \alpha_{\infty}=0.52
$$

In the case that is Reynolds for high flow, can be written: $\alpha^{*}=\alpha_{\infty}^{*}=1$

Also, for $f_{\beta^{*}}$ can be written:

$$
f_{\beta^{*}}=\left\{\begin{array}{c}
1 \chi_{k} \leq 0 \\
\frac{1+680 \chi_{k}^{2}}{1+400 \chi_{k}^{2}} \chi_{k}>0
\end{array}\right.
$$

Where in:

$$
\chi_{k}=\frac{1}{\omega^{3}} \frac{\partial k}{\partial x_{j}} \frac{\partial \omega}{\partial x_{j}}
$$

For $\beta^{*}$ we have:

$$
\beta^{*}=\beta_{i}^{*}\left(1+1.5 F\left(M_{t}\right)\right)
$$

Where $F\left(M_{t}\right)$, is the compressibility function

$$
F\left(M_{t}\right)=\left\{\begin{array}{c}
0 M_{t} \leq 0.25 \\
M_{t}^{2}-0.0625 M_{t}>0.25
\end{array}\right.
$$

And also:

$$
\beta_{i}^{*}=0.09\left(\frac{\frac{4}{15}+\left(\frac{R e_{t}}{8}\right)^{4}}{1+\left(\frac{R e_{t}}{8}\right)^{4}}\right)
$$

also, for $\beta$ and $f_{\beta}$ we have:

$$
\begin{gathered}
\beta=0.072\left[1-1.5 * \frac{\beta_{i}^{*}}{0.072} * F\left(M_{t}\right)\right] \\
f_{\beta}=\frac{1+70 \chi_{\omega}}{1+80 \chi_{\omega}}
\end{gathered}
$$

that $\chi_{\omega}$ are:

$$
\chi_{\omega}=\left|\frac{\Omega_{i j} \Omega_{j k} S_{k i}}{(0.09 \omega)^{3}}\right|
$$

That for $S_{i j}$ and $\Omega_{i j}$ we have:

$$
\begin{array}{r}
S_{i j}=\frac{1}{2}\left(\frac{\partial u_{i}}{\partial x_{j}}+\frac{\partial u_{j}}{\partial x_{i}}\right) \\
\Omega_{i j}=\frac{1}{2}\left(\frac{\partial u_{i}}{\partial x_{j}}-\frac{\partial u_{j}}{\partial x_{i}}\right)
\end{array}
$$

Model wilcox $k$ - $\omega$ in compared to standard model $k$ - $\varepsilon$ in some processes, including speed reduce and separation is due of adverse pressure gradient, works best. models $k-\varepsilon$, since that are high Reynolds models category (this means that in areas with high Reynolds number can provided good results), for solve the equations, in areas near wall, encountered with many problems. but model Wilcox $k-\omega$, can used for predict of changes in the turbulent variables until the edge of the solid walls.

\section{iv. k-w Shear Stress Transport Model}

Shear stress transport model k- $\omega$ is very similar to the standard model $\mathrm{k}-\omega$ but also, includes the following improvements:

a. Model $\mathrm{k}-\omega$ and model $\mathrm{k}-\varepsilon$, both in a mixing function, multiplied and two model added with together.

b. Shear stresses transport model has a Damped Cross Diffusion Derivative in equation $\omega$.

c. The definition of turbulence viscosity the change is located. in order to account for the effects of the main shear stresses transferring for turbulent flow.

d. Constant of model, compared to the standard model k- 
$\omega$ has changed.

These properties is the cause that this model for a wide range of currents, like flows with adverse pressure gradient, high section and the passing shock wave, compared to model $\mathrm{k}-\omega$, is much more accurate and safer.

this relationship of model is as follows:

$$
\begin{array}{r}
\frac{\partial}{\partial t}(\bar{\rho} k)+\frac{\partial}{\partial x_{j}}\left(\bar{\rho} \bar{u}_{j} k\right)=\frac{\partial}{\partial x_{j}}\left[\left(\mu+\frac{\mu_{t}}{\sigma_{k}}\right) \frac{\partial k}{\partial x_{j}}\right]+\tilde{G}_{k}-\rho \beta^{*} k \omega \\
\frac{\partial}{\partial t}(\bar{\rho} \omega)+\frac{\partial}{\partial x_{j}}\left(\bar{\rho} \bar{u}_{j} \omega\right)=\frac{\partial}{\partial x_{j}}\left[\left(\mu+\frac{\mu_{t}}{\sigma_{\omega}}\right) \frac{\partial \omega}{\partial x_{j}}\right]+G_{\omega}-\rho \beta \omega^{2}+D_{\omega}
\end{array}
$$

In this relationship $\tilde{G}_{k}, G_{\omega}, D_{\omega}$ as defined follows:

$$
\begin{gathered}
\tilde{G}_{k}=\min \left(G, 10 \rho \beta^{*} k \omega\right) \\
G_{\omega}=\frac{\alpha}{\vartheta_{t}} G \\
D_{\omega}=2\left(1-F_{1}\right) \rho \sigma_{\omega_{2}} \frac{1}{\omega} \frac{\partial k}{\partial x_{j}} \frac{\partial \omega}{\partial x_{j}}
\end{gathered}
$$

In this model, $\alpha_{\infty}$ in equation (53) is obtained from the following equation:

$$
\begin{gathered}
\alpha_{\infty}=F_{1} \alpha_{\infty_{1}}+\left(1-F_{1}\right) \alpha_{\infty_{2}} \\
\text { That: }\left\{\begin{array}{l}
\alpha_{\infty_{1}}=\frac{\beta_{i_{1}}}{\beta_{\infty}^{*}}-\frac{0.41^{2}}{\sigma_{\omega_{1}} \sqrt{\beta_{\infty}^{*}}} \\
\alpha_{\infty_{2}}=\frac{\beta_{i_{2}}}{\beta_{\infty}^{*}}-\frac{0.41^{2}}{\sigma_{\omega_{2}} \sqrt{\beta_{\infty}^{*}}}
\end{array}\right.
\end{gathered}
$$

And $v_{t}$ is the kinematic viscosity turbulence:

$$
\mu_{t}=\frac{\rho k}{\omega} \frac{1}{\max \left(\frac{1}{\alpha^{*},} \frac{S F_{2}}{a_{1} \omega}\right)}, a_{1}=0.31
$$

$$
F_{2}=\tanh \left(\arg _{2}^{2}\right), \arg _{2}=\max \left[\frac{2 \sqrt{k}}{0.09 \omega y}, \frac{500 v}{\omega y^{2}}\right]
$$

$$
F_{1}=\tanh \left(\arg _{1}^{4}\right), \arg _{1}=\min \left(\max \left[\frac{\sqrt{k}}{0.09 \omega y}, \frac{500 v}{\omega y^{2}}\right], \frac{4 \rho k}{\sigma_{\omega_{2}} D_{\omega}^{+} y^{2}}\right)
$$

$$
D_{\omega}^{+}=\max \left[2 \rho \frac{1}{\sigma_{\omega_{2}}} \frac{1}{\omega} \frac{\partial k}{\partial x_{j}} \frac{\partial \omega}{\partial x_{j}}, 10^{-10}\right]
$$

And also, $\Omega$ is the absolute value of rotation.

In near the walls that model $k_{-} \omega$ is more valid, we have:

$$
\begin{gathered}
\sigma_{k_{1}}=1.176, \sigma_{w_{1}}=2, \beta_{1}=0.075, \beta_{\infty}^{*}=0.09, \alpha_{1}=\frac{5}{9} \\
\sigma_{k_{2}}=1, \sigma_{w_{2}}=1.168, \beta_{2}=0.0828 \\
\beta^{*}=0.09, \alpha_{1}=0.872
\end{gathered}
$$

Also have:

$$
\varepsilon=\beta^{*} \omega k
$$

\section{Geometrical Production of Exchanger}

For geometrical examined in this study is the use of gambit software. figure below shows a view of the shell and tube exchangers with a simple transvers baffle that in this the software is designed and modeled.

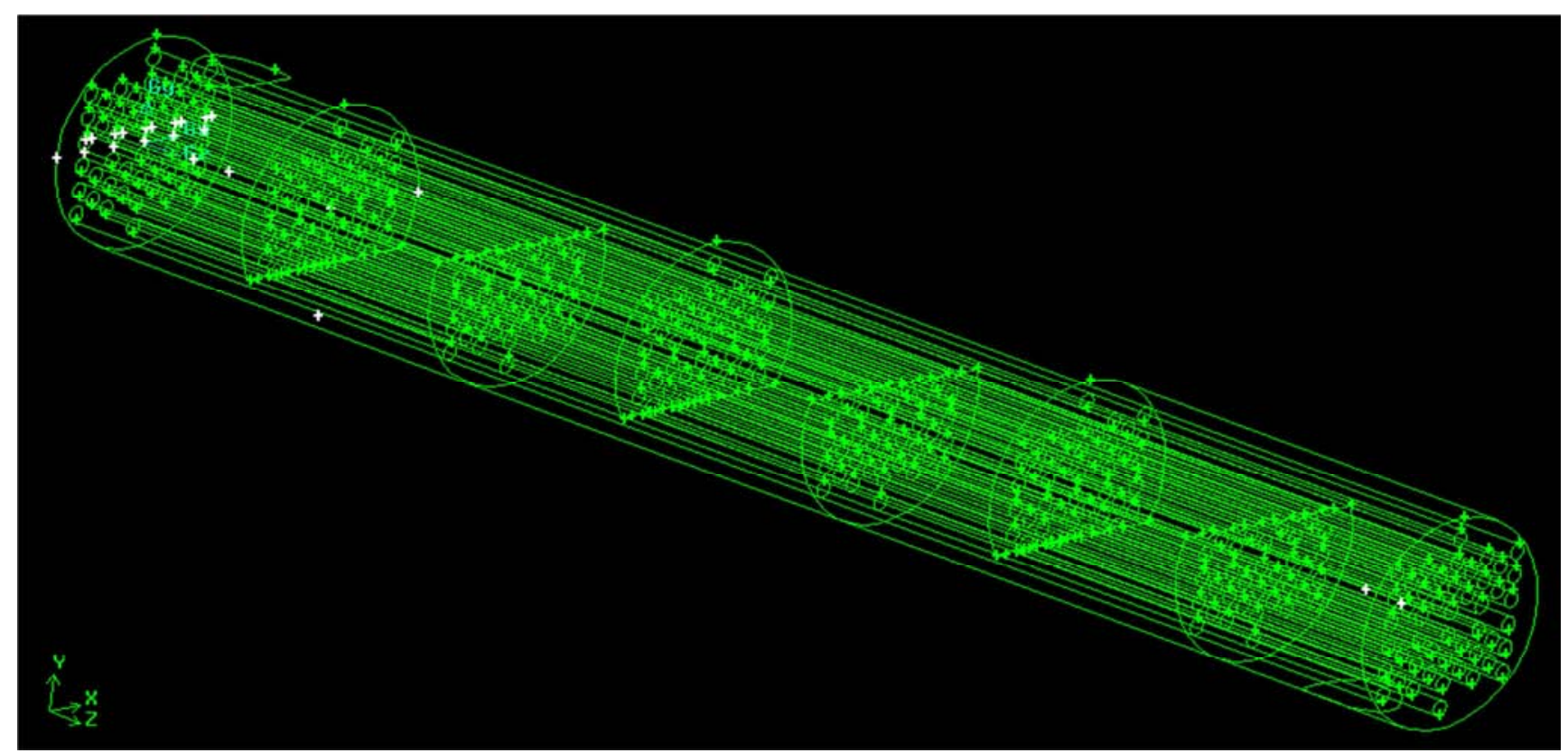

Figure 1. A view of the segmental baffle geometry in gambit. 


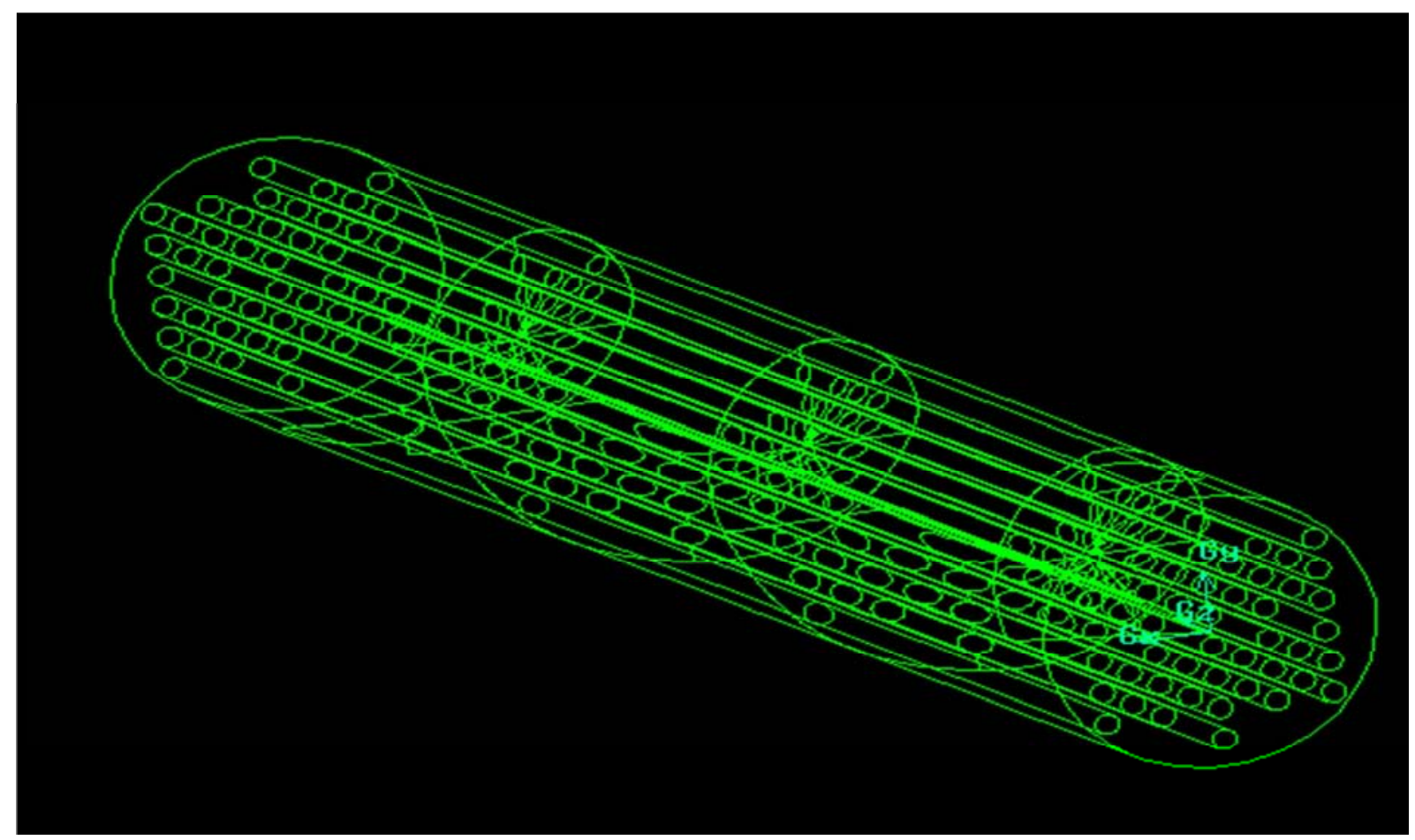

Figure 2. A view of the spiral baffle geometry in gambit.
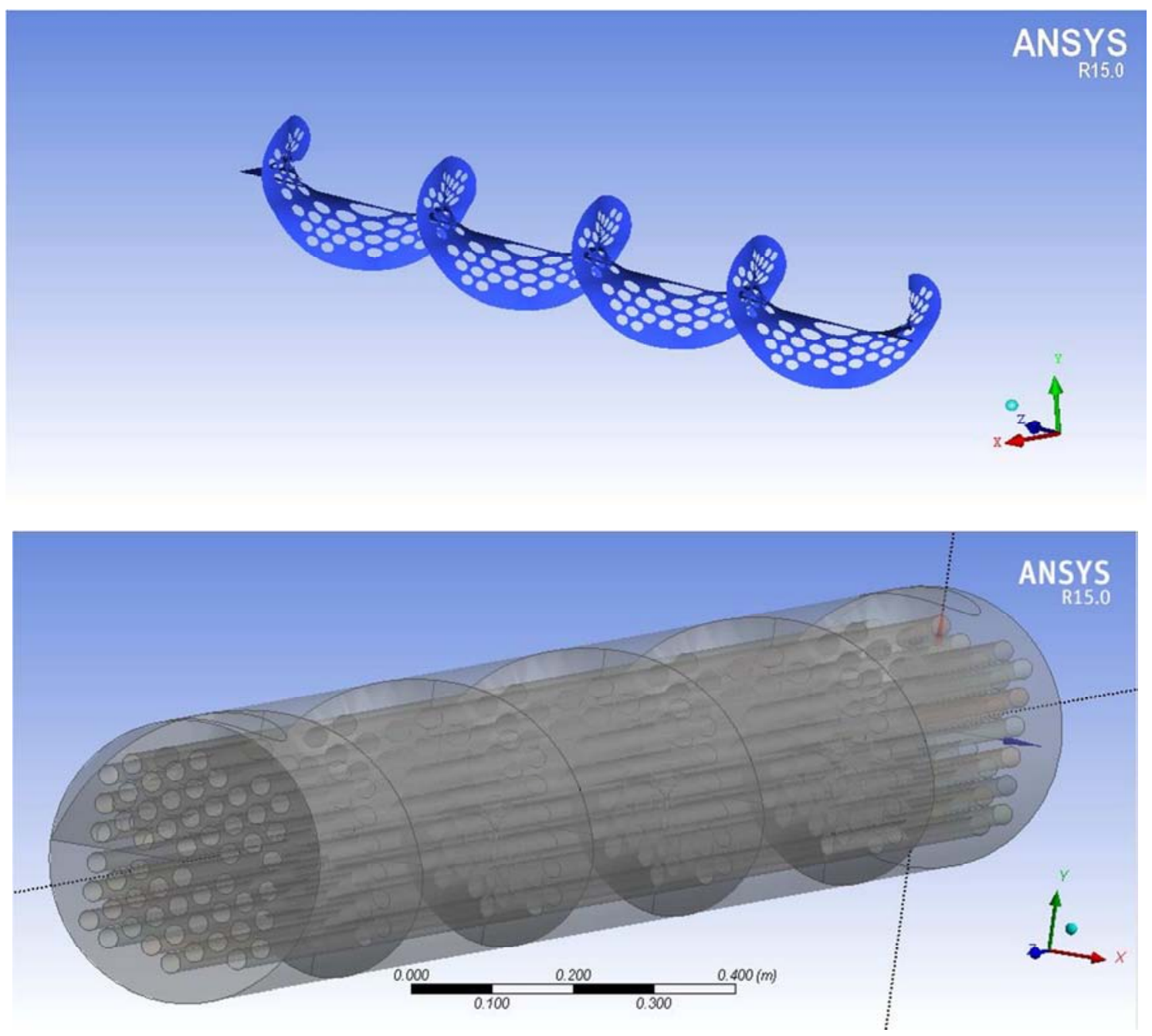

Figure 3. A view of the spiral baffle geometry. 


\section{Generats the Computational Grid}

Computational network is produced in gambit software. due to geometry of volumes produced, during the design of exchanger are complex, production of organized network in the computational domain, is working very hard. so, in all previous research, from network of computing without organization, is used for the numerical solution of exchanger. on this basis, in this study, is used from network of without organization with Tetrahedral cells in three dimension and Triangular cells in two dimension.

Figure 4 show view of the production network in the exchanger input.

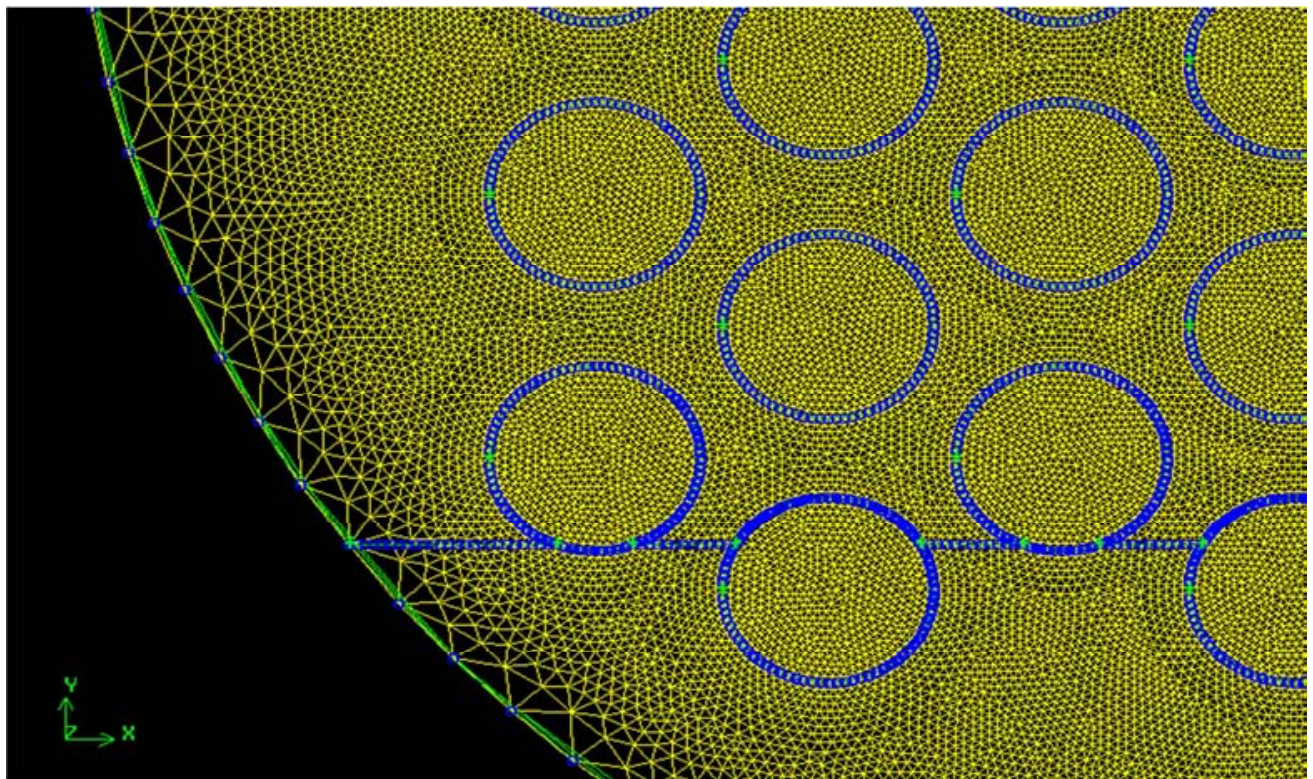

Figure 4. View of the production network in the exchanger input.

Figure 5 also shows a view of the network on the outer body of shell.

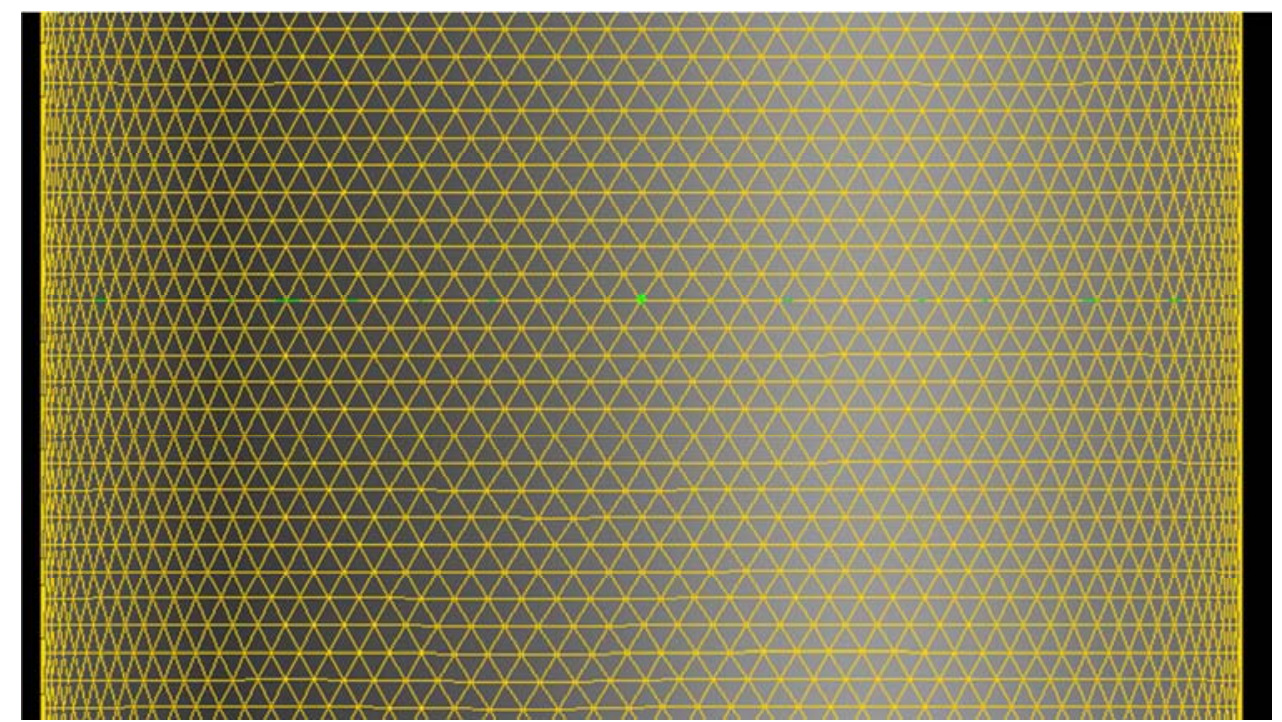

Figure 5. A view of the shell outer body network.

\section{Validation and Network Study}

For validation and network study, 4 network with numbers of computational cells 875000, 2000000, 3500000, 13000000 were compare and investigated. according to the results of this exchanger in the industry, is propane input with flowrate 80 cubic meters per hour and temperature $35.5^{\circ} \mathrm{C}$. for entering water steam of the shell, is $1628 \mathrm{~kg} / \mathrm{h}$ for input flowrate and is $161.6 \mathrm{C}$ for input, propane outlet temperature reached about $65^{\circ} \mathrm{C}$.

From this information is used for check of the accuracy of numerical solutions on any network.

In the chart 6 the results of this analysis can be seen. 


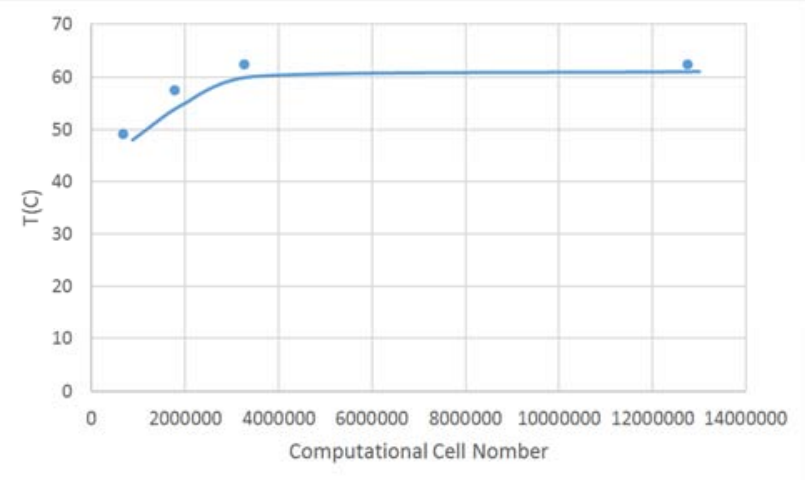

Figure 6. Propane outlet temperature changes depending on the change in the number of computational cells.

Also, in figure 7 it has been shown, error of output temperature with numerical solution from actual data

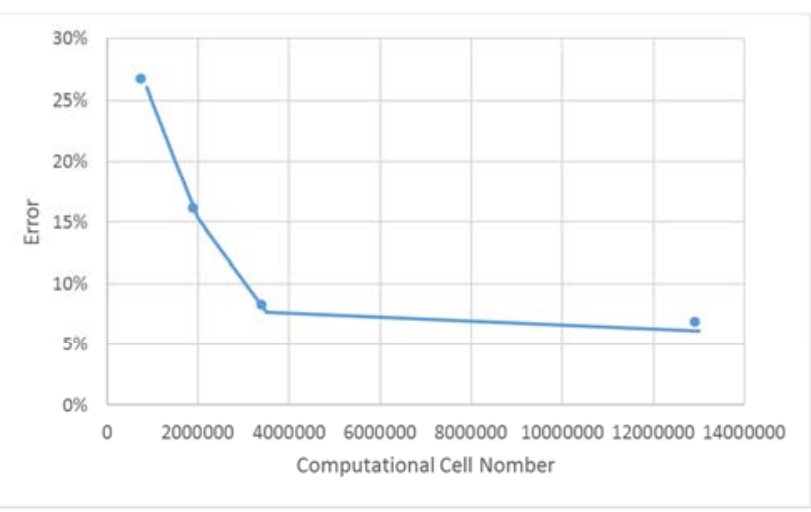

Figure 7. Error of the numerical solution of different networks.

It can be seen that error of solution in the networks in after 3500000 , is less than $10 \%$ and is acceptable.

In figure 8 and 9 also, like previous charts, for pressure drop in shell of networks have been checked that it can be seen, network 3500000 in compared with other networks, the accuracy is acceptable and also, in compared with network 13000000 cells, has faster convergence.

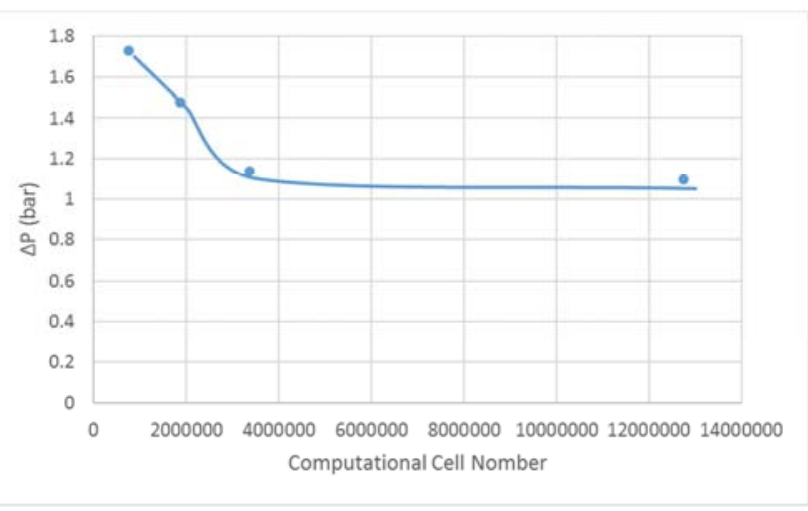

Figure 8. The pressure drop in the shell in different networks.

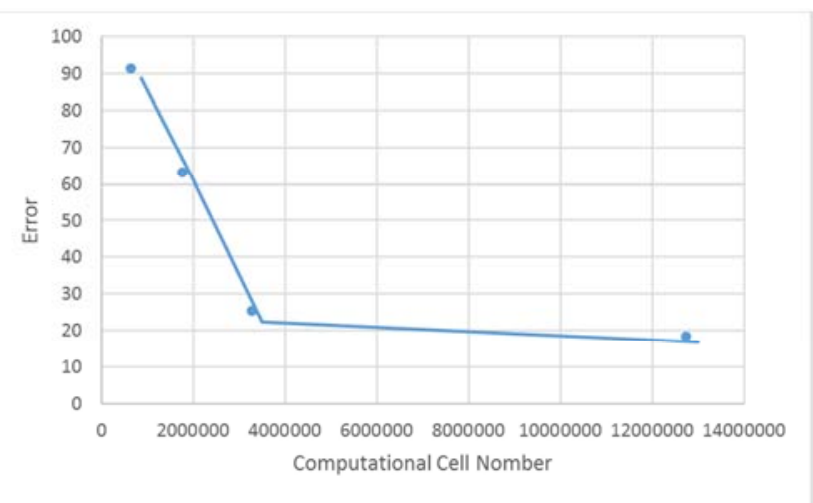

Figure 9. Failure to obtain of pressure drop in various network.

\section{Numerical Results of Analysis}

specifications of exchangers models are investigated and working fluids through of exchanger

According to the research objectives, 5 of model, shell and tube exchanger, has been studied in table 2 .

Table 2. Models examined in the study.

\begin{tabular}{|c|c|c|c|c|c|}
\hline MODEL & model 1 & model 2 & model 3 & model 4 & model 5 \\
\hline $\begin{array}{l}\text { Kind of baffle } \\
\text { property }\end{array}$ & $\begin{array}{l}\text { segmental } \\
7 \text { baffle }\end{array}$ & $\begin{array}{l}\text { helical } \\
\text { Angle } 35\end{array}$ & $\begin{array}{l}\text { helical } \\
\text { Angle } 40\end{array}$ & $\begin{array}{l}\text { helical } \\
\text { Angle } 45\end{array}$ & $\begin{array}{l}\text { helical } \\
\text { Angle } 50\end{array}$ \\
\hline
\end{tabular}

The first model that is segmental baffle, is tried to be a model, like to industrial exchanger used in south pars gas complex.

It should be noted that is considered, helical angle with the longitudinal axis of the exchanger.

Also, the working fluids in the shell and tube, has been shown, according to the shell and tube with available information in plot 3

Table 3. Transient fluids characteristics of shell and tube.

\begin{tabular}{lllll}
\hline & Fluid name & density $\left(\mathbf{k g} / \mathbf{m}^{\mathbf{3}}\right)$ & $\mathbf{C p}(\mathbf{j} / \mathbf{k g} . \mathbf{k})$ & Thermal conductivity (w/m.k) \\
\hline Fluid of passing from shell & Water steam & 0.5542 & 2014 & 0.0261 \\
Fluid of passing from tube & propane & 1.191 & 1549 & 0.0177 \\
\hline
\end{tabular}

Table 4. Profile steal tubes and shells and baffles.

\begin{tabular}{lllll}
\hline & material & density $\left(\mathbf{k g} / \mathbf{m}^{\mathbf{3}}\right)$ & Cp (j/kg.k) & Thermal conductivity (w/m.k) \\
\hline tube & A-334 & 7567.2 & 445.5 & 615.456 \\
shell & A-516 GR-60 & 7861.1 & 447.688 & 622.64 \\
baffle & A-350 LF2 & 7498.3 & 451.33 & 619.78 \\
\hline
\end{tabular}




\subsection{Boundary Condition and Initial of Problem}

In this problem, is propane input with flowrate 2 cubic meters per hour and temperature $35.5^{\circ} \mathrm{C}$. for entering water steam of the shell, is $1628 \mathrm{~kg} / \mathrm{h}$ for input flowrate and is $161.6^{\circ} \mathrm{C}$ for input temperature.

\subsection{Choose a Suitable Turbulence Model}

Considering Fluid flow is turbulent in exchanger, one of the important parts of research, turbulence model is the right choice. for this purpose, three turbulence models RNG K- $\varepsilon$ ، $\mathrm{K}-\omega$ Standard and

SST K- $\omega$ was checked for exchanger with segmental baffle and the number of cells by 3500000 , that in the three solutions, propane temperature output accuracy and speed convergence of three models, were compared together.

Accuracy of RNG K- $\varepsilon$ and SST K- $\omega$ models are almost identical, difference is that convergence of model RNG K- $\varepsilon$ is faster than SST K- $\omega$ model.

Standard K- $\omega$ model has less accurate than the other two models. so, model RNG K- $\varepsilon$ is used as the model of choice for continuation of analysis.

\subsection{Comparing the Model Results}

Based on information obtained in the previous section from computational grid with 3500000 cells is used for all of the models.

Also, is used from SIMPLE algorithms and second order discrete in equations solve.

In figure 10 has determined Changes of convection coefficient of the shell inside fluids for baffle different states of shell inside.

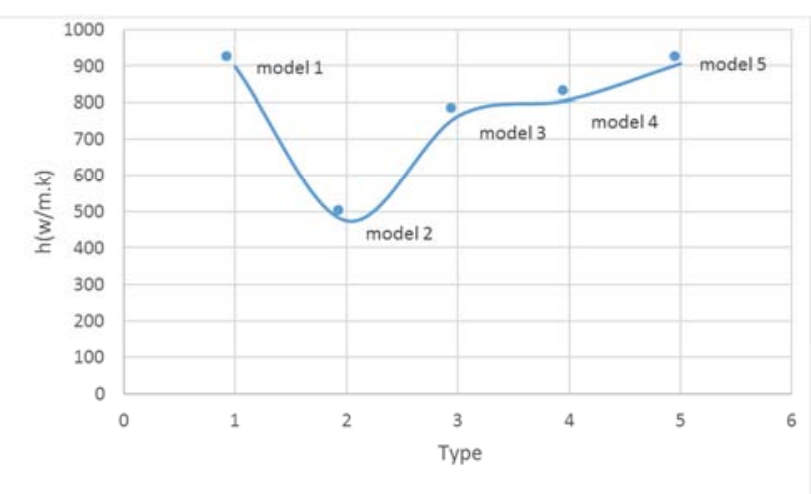

Figure 10. Changes of convection coefficient of the shell inside fluids for baffle different states of shell inside.

As you see, model 5 with angle of baffle 50 degree, has the most rate of the heat transfer coefficient.

After model 5, model 1 that is simple segmental baffle,, has the most rate of the heat transfer.

Figure 11 has determine compare the pressure drop of inside the shell for different models of baffle.

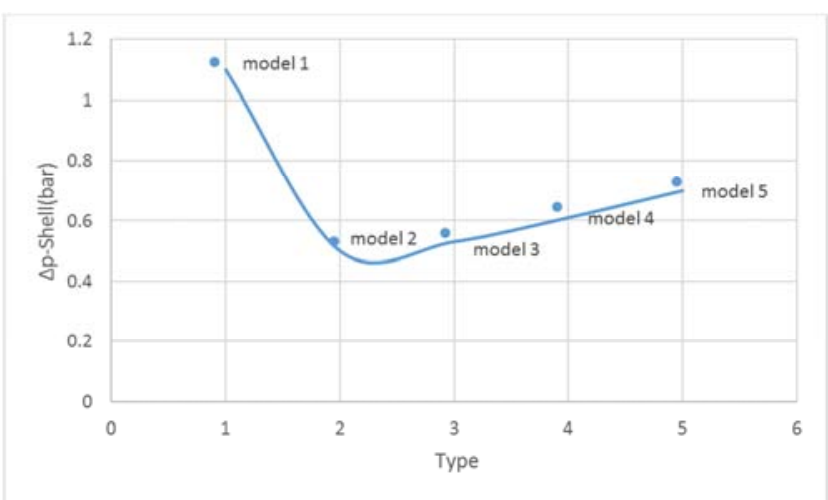

Figure 11. Compare the pressure drop of inside the shell for different models of baffle.

From figure 11, it is observed that the most of the pressure drop is related in exchanger with segmental baffle.

For exchangers with helical baffle, by increasing the baffle angle to the longitudinal axis, with the increase in pressure drop.

The parameter that with respect of heat transfer and pressure drop, can more efficient model for us to determine, is ratio of $h / \Delta p$. whatever this ratio be the higher, of course is the better.

Figure 12 has determined ratio of $h / \Delta p$ for different models of baffle.

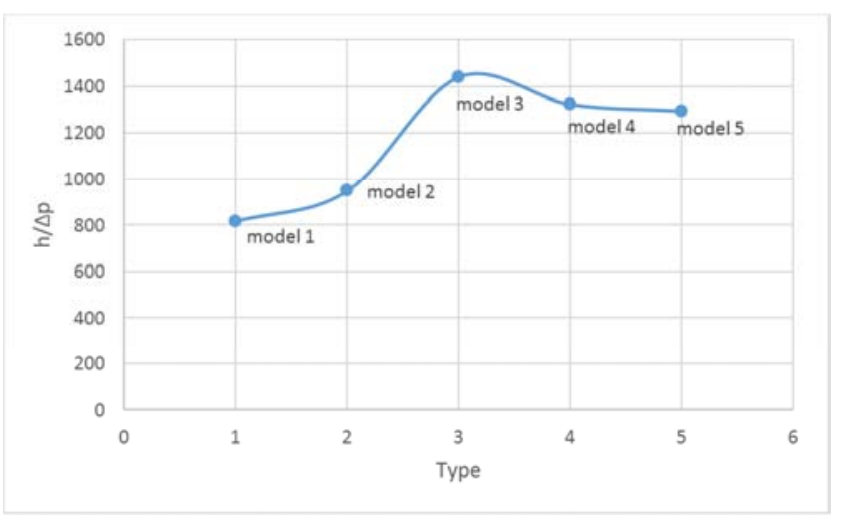

Figure 12. $h / \Delta p$ ratio for different models of baffle.

From figure 12, it is clear that model 3 with angle of 40 degree, has the most of ratio $\mathrm{h} / \Delta \mathrm{p}$. model 1 with segmental baffle, has the lowest of ratio that is indicative, lack of suitability this model.

Of course, in a place that temperatures have a major role in the problem and more important goal is to increase heat transfer between two fluids, may is used from the model that has higher heat transfer and it is ignored rate of higher of pressure drop.

For example, in this problem that the goal is to increase the output temperature of propane, surely, model 5 is the better option. figure 13 show propane outlet temperature for baffle different models. 


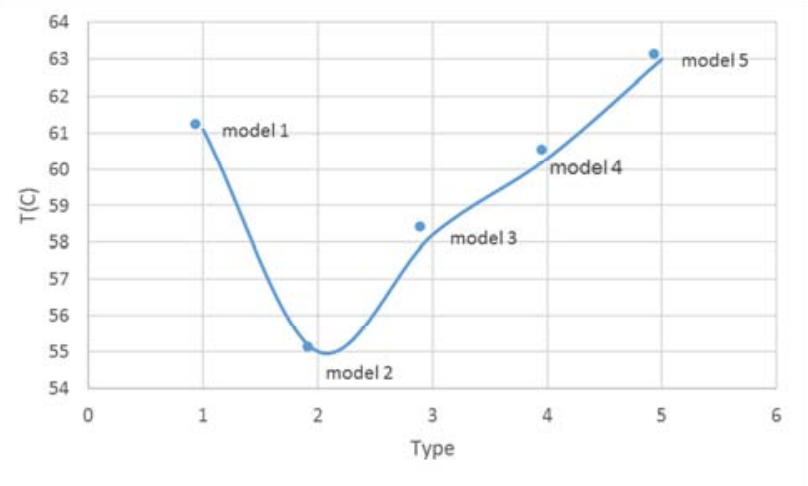

Figure 13. Propane outlet temperature.

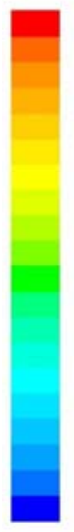

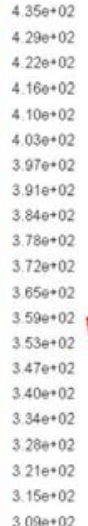

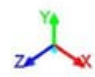

Figure 14. The temperature distribution inside the exchanger tubes with segmental baffle.

As you can see because opposed to shell and tubes flow, as we get closer to the outlet of tubes, tubes surface temperature has risen.

Figure 15 has showed temperature distribution of the baffles in segmental state.
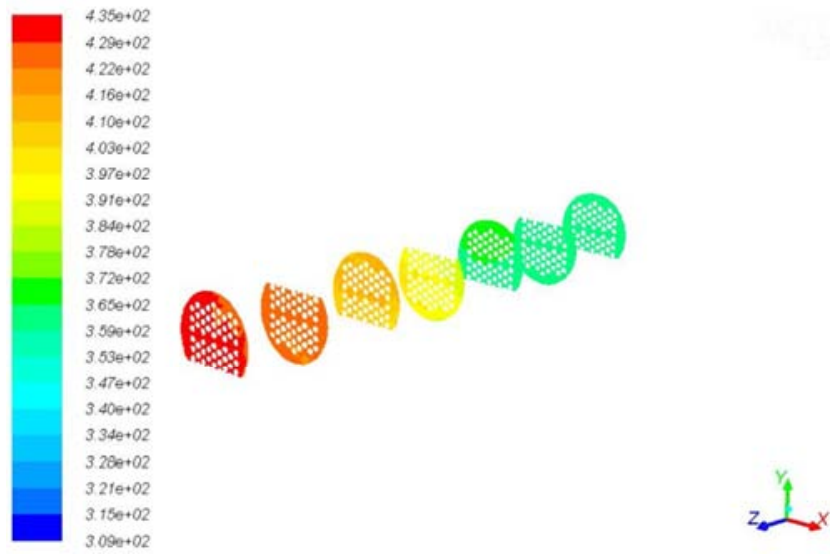

Figure 15. Temperature distribution of the baffles.

As you can see in segmental simple baffle, pressure drop is high. this is due to the formation of vortices is behind the baffle.

Of course, it would help to increase of heat transfer coefficient because of flow turbulence.
Figure 16 show view of the creation of rest areas and vortex-shaped.
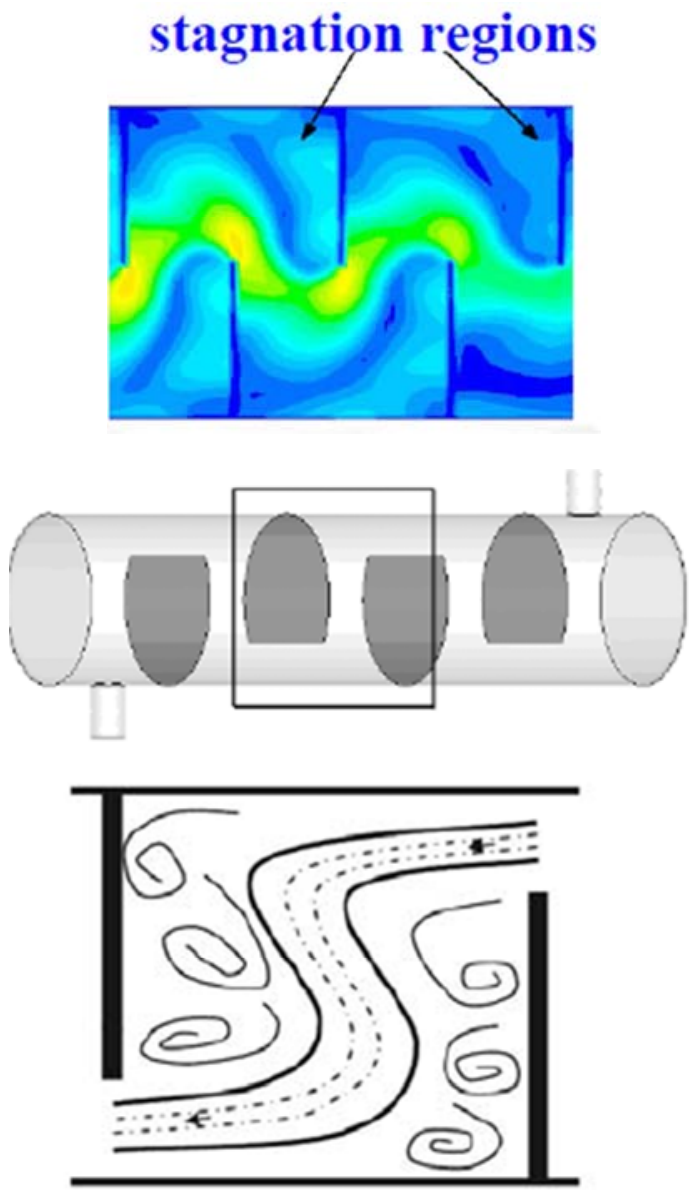

Figure 16. View of the creation of rest areas and vortex-shaped.

Figure 17 show flow in exchanger with helical baffle that because of the shape of baffle is less vortices and reduced pressure drop in the shell.
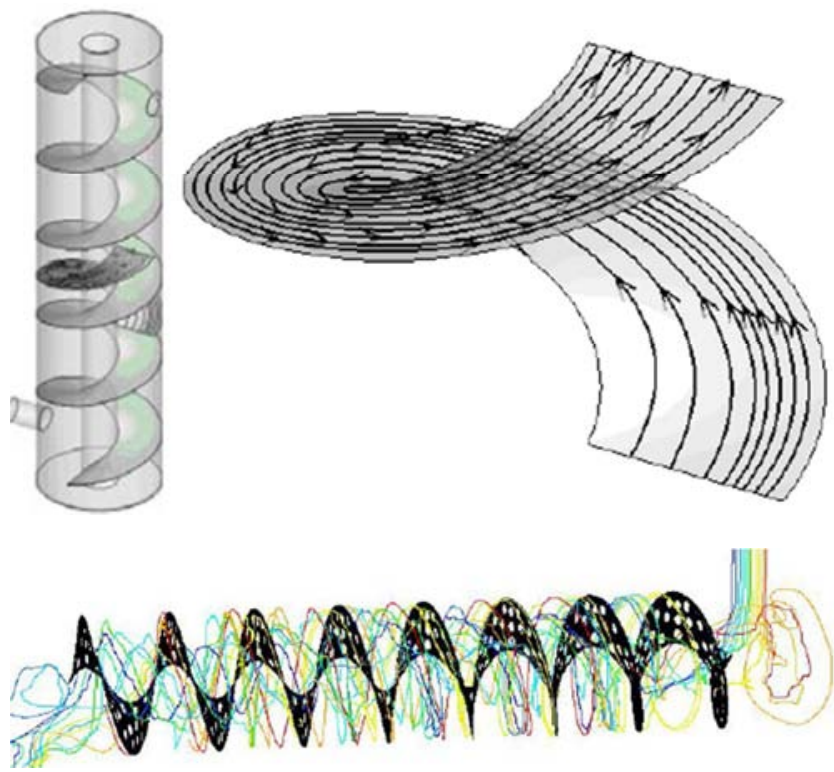

Figure 17. Flow in exchanger with helical baffle. 


\section{Offers}

Due to the high number of computational cells in such a matter, by taking a large number baffle model and more angles takes many times but the results can be more accurate from flow behavior and obtained heat transfer in exchanger at baffle different angles. also, With more models can by using genetic algorithm, the optimal angle to achieve for higher efficiency of exchanger.

Also, at different Reynolds or in other words, in the flowrates of the fluid inlet deferent, the other results can described for heat transfer and pressure drop in other models according to flow.

\section{Conclusion}

In this research using numerical solution effect of changing baffle from segmental state to helical state for an industrial exchanger was studied. also, affect of change of helical angle on heat transfer and pressure drop was studied. using network study found that network with 3500000 computational cells is the best option for the numerical solution this exchanger.

Also, with the resulting network, three turbulence models RNG K- $\varepsilon$ ، K- $\omega$, SST K- $\omega$ for exchanger with segmental baffle that result shown that model RNG K- $\varepsilon$ in addition to sufficient accuracy, convergence is good in compare to other models.

With this information, 4 exchangers models with different helical angle were compared with simple exchanger with segmental baffle. survey showed that model 5 with the helical angle of 50 degree, most propane outlet temperature and heat transfer rate that is the highest among other exchangers. but if pressure drop in the shell is also important, it is not optimal. model 3 with an angle of the 40 degree, the highest of the $\mathrm{h} / \mathrm{dp}$ that is represents rate of heat transfer to pressure drop.

The results of this study can be used in exchangers used in various industries such as oil and gas industries.

\section{Nomenclature}

\section{Latin symbols}

$\begin{array}{ll}\mathrm{T} & \text { fluid temperature }(\mathrm{K}) \\ \mathrm{Q} & \text { conservative variable vector } \\ \tilde{G}, \tilde{F}, \tilde{E} & \text { displacement fluids vector } \\ E v, F v, G v & \text { viscous fluids vector } \\ \text { he } & \text { introduced the total energy } \\ M t & \text { Mach of turbulent flow } \\ \mathrm{cp} & \text { specific heat }\left(\mathrm{Jkg}^{-1} \mathrm{k}^{-1}\right) \\ \Delta \mathrm{p} & \text { overall pressure drop }(\mathrm{Pa}) \\ \mathrm{DT} & \text { logarithmic mean temperature difference }(\mathrm{K}) \\ \mathrm{U}, \mathrm{V}, \mathrm{W} & \text { velocities in different directions }\left(\mathrm{ms}^{-1}\right) \\ \mathrm{X}, \mathrm{Y}, \mathrm{Z} & \text { Cartesian coordinates system }\left(\mathrm{mm}^{2}\right) \\ \mathrm{Greek} \mathrm{symbols} & \\ \mu & \text { dynamic viscosity }\left(\mathrm{kgm}^{-1} \mathrm{~s}^{-1}\right) \\ \mu \mathrm{t} & \text { turbulent dynamic viscosity }\left(\mathrm{kgm}^{-1} \mathrm{~s}^{-1}\right) \\ v \mathrm{t} & \text { turbulent dynamic viscosity }\left(\mathrm{kgm}^{-1} \mathrm{~s}^{-1}\right)\end{array}$

$\begin{array}{ll}v & \text { kinematic viscosity }\left(\mathrm{m}^{2} \mathrm{~s}^{-1}\right) \\ \varepsilon & \text { dissipation rate of turbulent }\left(\mathrm{m}^{2} \mathrm{~s}^{-3}\right) \\ \rho & \text { density }\left(\mathrm{kg} \mathrm{m}^{-3}\right) \\ \mathrm{a} & \text { speed of sound } \\ \sigma \mathrm{k} & \text { Prandtl number of } k \\ \sigma \varepsilon & \text { Prandtl number of } \varepsilon \\ \Omega & \text { rotation absolute value } \\ \lambda & \text { thermal conductivity }\left(\mathrm{Wm}^{-1} \mathrm{k}^{-1}\right) \\ \text { Subscripts } & \\ \text { In } & \text { inlet } \\ \text { Out } & \text { outlet } \\ \mathrm{S} & \text { shell side } \\ \mathrm{t} & \text { tube side }\end{array}$

\section{References}

[1] Holman J. P., 2002. Heat Transfer, 9th Edition, McGraw-Hill.

[2] Mills A. F., 1992. Heat transfers, Irwin, USA.

[3] Patankar, S. V., 1980. Numerical Heat Transfer and Fluid Flow", Hemisphere, New York.

[4] Shah R. K., Sekulic D. P., 2003. Fundamentals of Heat Exchanger Design, John Wiley and Sons, Inc., NJ.

[5] Treybal R. E., 1990. Mass-Transfer Operation, 3rd Edition, Tokyo.

[6] Wilcox D. C., 1994. Turbulence Modeling for CFD. DCW Industries, Inc, California.

[7] Anderson D. A., Tannehill J. C. and Pletcher R. H, 1998. Computational Fluid Mechanic And Heat Transfer, Mc-GrawHill Book Company, Washington D. C, New York And London.

[8] Bahiraei M., Hangi M., Saeedan M., 2015. A novel application for energy efficiency improvement using nanofluid in shell and tube heat exchanger equipped with helical baffles, Energy, Vol. 93, part 2, PP. 2229-2240.

[9] Dizaji H. S., Jafarmadar S., Hashemian M., 2015. The effect of flow, thermodynamic and geometrical characteristics on exergy loss in shell and coiled tube heat exchangers, Energy conversion and management, Vol. 91, PP. 678-684.

[10] Gao B., Bi Q., Nie Z. and Wu J., 2015. Experimental study of effects of baffle helix angle on shell-side performance of shelland-tube heat exchangers with discontinuous helical baffles. Experimental thermal and fluid Science, Vol. 68, PP. 48-57.

[11] Yang J. and Liu W., 2015. Numerical Investigation on a novel shell-and-tube heat exchanger with plate baffles and experimental validation, Energy conversion and management, Vol 101, PP. 689-696.

[12] Yang J. F., Zeng M., Wang Q. W., 2015. Numerical investigation on combined single shell and tube heat exchanger with two-layer continuous helical baffles, International Journal of Heat and Mass transfer, Vol. 84, PP 103-113.

[13] Vildanov A. F., 2002. Technology Conceotion for Desining a Commercial Plant For Propane, Butane and Naphta Treatment for Kharg PCC Refinery, Energy conversion and management, Vol. 43, part 2, PP. 229-2140. 